\title{
Effect of varying pulse interval in atrial fibrillation on left ventricular function in man
}

\author{
D. G. Gibson, G. Broder, and E. Sowton \\ From the National Heart Hospital and Institute of Cardiology, London W.I
}

The effect of spontaneous variation in $R R$ interval due to atrial fibrillation on ventricular ejection was studied in 19 patients with aortic Starr-Edwards prostheses. Reduction in the interval between the onset of ventricular activation and the opening sound of the prosthesis (QAI) is due to an increase in the initial force acting on the ball. Negative correlation was present in all patients between $Q A I$ interval and the RR interval immediately preceding, which was associated with progressive reduction in the gradient across the prosthesis during diastole. Positive correlation was present in 14 out of 19 patients between the second preceding RR interval and QAI interval, which was not due to changes in ventricular filling or end-diastolic pressure gradient across the prosthesis, and appeared to reflect a direct positive inotropic effect of $R R$ interval. In 5 patients, all with evidence of heart failure, this effect was not shown. These findings have been expressed in terms of multiple regression equations, and related to the clinical features of atrial fibrillation.

Beat-to-beat variations in the amplitude and rate of rise of left ventricular and aortic pressure have long been recognized in atrial fibrillation (Wiggers, 1915; Einthoven and Korteweg, 1915), and have been related to the effects of irregularity in pulse interval on ventricular filling and aortic pressure. In addition, there is much evidence to suggest that the interval between beats has a direct effect on the contractile state of the left ventricle (Bowditch, 1872; Woodworth, 1902; Koch-Weser and Blinks, 1963).

In order to assess the possible importance of these effects in atrial fibrillation in man, a study was made of 19 patients with StarrEdwards prostheses in the aortic position. A phonocardiographic method of assessing the initial rate of movement of the ball at the onset of left ventricular systole was used, allowing changes in left ventricular function to be determined reproducibly on a beat-to-beat basis (Gibson, Broder, and Sowton, 1970). This has been shown to be a sensitive method of detecting alterations in the contractile state of the left ventricle which is little affected by changes in ventricular filling.

\section{Methods}

Nineteen patients were studied, in whom a StarrEdwards prosthesis had been inserted in the aortic position I to 24 months previously. Clinical details are given in Table $\mathbf{r}$. All were in atrial fibrillation

Received 2 October 1970. and all were taking digitalis, diuretics, and anticoagulant therapy. In 10 the mitral valve had also been replaced, and in $I$ the tricuspid as well as mitral and aortic valves. One additional patient had had a mitral valvotomy.

Phonocardiograms and a simultaneous electrocardiogram were recorded with the patient in the supine position, using a Cambridge photographic recorder at a paper speed of $100 \mathrm{~mm} / \mathrm{sec}$. The microphone was at the lower left sternal edge. In 3 patients (Cases I-3), observations were made during postoperative cardiac catheterization. Systemic arterial pressure was recorded from a No. 8 catheter in the aortic root, and pulmonary wedge (PC) pressure from a No. 7 Cournand catheter. In these patients, phonocardiograms were recorded with a Sanborn microphone at the lower left sternal edge, and pressures were measured with Statham P23Gb strain gauge transducers. Pressure traces, phonocardiogram, and electrocardiogram were recorded photographically at a paper speed of $100 \mathrm{~mm} / \mathrm{sec}$ at rest, and after 2 minutes' supine exercise with a bicycle ergometer.

Measurements The timing of heart sounds was measured from the first high frequency component. The QAI interval was measured from the onset of the $Q$ wave to the opening sound of the prosthesis ( $\mathrm{Ar}$ ), the ejection time from the aortic pressure pulse, and the $\mathrm{ArAz}_{2}$ interval as the time between the opening and closing sounds (A2) of the prosthesis. Ball travel time (BTT) was taken as ejection time less $\mathrm{ArA2}_{2}$ interval (Gibson et al., 1970). $\Delta P$, the end-diastolic gradient across the prosthesis, was taken as the difference between end-diastolic aortic and end-diastolic wedge pres- 
TABLE I Clinical details

\begin{tabular}{|c|c|c|c|c|c|c|}
\hline \multirow{2}{*}{$\begin{array}{l}\text { Case } \\
\text { No. }\end{array}$} & \multirow{2}{*}{$\begin{array}{c}\text { Age } \\
(y r)\end{array}$} & \multirow[t]{2}{*}{ Sex } & \multirow[t]{2}{*}{ Operation } & \multirow[t]{2}{*}{ Disability } & \multicolumn{2}{|l|}{ Chest x-ray } \\
\hline & & & & & $\begin{array}{l}\text { Cardio- } \\
\text { thoracic } \\
\text { ratio }(\%)\end{array}$ & $\begin{array}{l}\text { Pulmonary } \\
\text { vascular } \\
\text { congestion }\end{array}$ \\
\hline $\mathbf{I}$ & 48 & $M$ & Aortic Starr valve & II & 53 & 0 \\
\hline 2 & 49 & $M$ & Aortic Starr valve & $\circ$ & 48 & 0 \\
\hline 3 & 50 & $M$ & Aortic Starr valve & III & 57 & ++ \\
\hline 4 & 52 & $\mathbf{F}$ & Aortic and mitral Starr valves & I & 66 & + \\
\hline 5 & 55 & $\mathbf{F}$ & Aortic and mitral Starr valves & $\circ$ & $6 I$ & 0 \\
\hline 6 & $4 \mathrm{I}$ & $\mathbf{F}$ & Aortic and mitral Starr valves & I & 63 & $\circ$ \\
\hline 7 & 48 & F & Aortic, mitral, and tricuspid Starr valves & II & 70 & ++ \\
\hline 8 & 53 & $\mathbf{M}$ & Aortic Starr valve & $\circ$ & 47 & $\circ$ \\
\hline 9 & 62 & $\mathbf{M}$ & Aortic Starr valve & $\circ$ & 58 & + \\
\hline I0 & 64 & $\mathbf{M}$ & Aortic and mitral Starr valves & II & 54 & ++ \\
\hline II & 43 & $M$ & Aortic and mitral Starr valves & II & 61 & + \\
\hline 12 & 59 & $\mathbf{M}$ & Aortic Starr valve & II & 59 & $\circ$ \\
\hline 13 & 47 & M & Aortic and mitral Starr valves & II & 59 & ++ \\
\hline 14 & 52 & $\mathbf{M}$ & Aortic and mitral Starr valves & I & 53 & o \\
\hline 15 & 55 & $\mathrm{~F}$ & Aortic Starr valve & I & 72 & + \\
\hline 16 & 55 & $\mathbf{M}$ & Aortic Starr valve & I & 56 & + \\
\hline 17 & 53 & $\mathbf{F}$ & Aortic and mitral Starr valves & o & 62 & + \\
\hline 18 & 57 & $\mathbf{F}$ & Aortic and mitral Starr valves & I & 70 & o \\
\hline 19 & 52 & $\mathbf{F}$ & Aortic and mitral Starr valves & II & 55 & + \\
\hline
\end{tabular}

- Pulmonary vascular congestion: + Dilated upper lobe vessels only. + + Lymphatic lines, in addition to dilated upper lobe vessels.

b Disability: $\mathrm{O}=$ Normal exercise tolerance; $\mathrm{I}=$ dyspnoea on severe exercise; $\mathrm{II}=$ dyspnoea on moderate exercise; III = dyspnoea on any exercise.

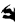

sures. The $R R$ interval immediately preceding the beat in question is referred to as $R R^{\prime}$ and the

- RR interval before this, i.e. two before the beat in question, as $R R^{\prime \prime}$.

Statistical analysis In all cases a linear relation

- was assumed between variables, and regression analysis performed by the method of least squares. For the relation between ball travel time and QAI interval an equation of the form

$$
\text { BTT }=a+b Q A I
$$

was assumed, where $a$ and $b$ are constants. a, b, r, the regression coefficient, and $P$, the probability that $\mathbf{r}$ differs from zero, are given in Table 2 . A similar method was used to investigate the relation between $\Delta P$ and $R R$ interval, the equation being

$$
\Delta \mathrm{P}=\mathrm{a}+\mathrm{bRR}^{\prime}(\text { Table } 3) .
$$

TABLE 2 Relation between ball travel time and QAI interval in Cases I-3

\begin{tabular}{llllll}
\hline $\begin{array}{l}\text { Case } \\
\text { No. }\end{array}$ & State & $\begin{array}{l}\text { Slope } \\
(b)\end{array}$ & $\begin{array}{l}\text { Intercept } \\
(a) \\
(\mathrm{msec})\end{array}$ & $r$ & $P$ \\
\hline & & & & \\
\hline $\mathbf{1}$ & Rest & 0.60 & -28.6 & 0.89 & $<0.001$ \\
& Exercise & 0.61 & -27.5 & 0.81 & $<0.001$ \\
& Rest & 0.49 & +3.9 & 0.94 & $<0.001$ \\
& Exercise & 0.49 & -1.9 & 0.85 & $<0.001$ \\
& Rest & 0.62 & -46.5 & 0.91 & $<0.001$ \\
& Exercise & 0.61 & -46.4 & 0.82 & $<0.001$ \\
\hline
\end{tabular}

$\mathbf{B T T}=\mathbf{b} \times \mathrm{QAI}+\mathbf{a}$.
In order to study the relation between $R R$ interval and QAI interval, multiple regression analysis was performed, on the assumption that for any particular beat QAI could be regarded as a function of $\mathbf{R R}^{\prime}$ and $\mathbf{R R}^{\prime \prime}$ :

$$
Q A I=a+b R R^{\prime \prime}+c R R^{\prime},
$$

where $a, b$, and $c$ are constants which are given in Table 4, together with $r$, the coefficient of multiple regression. In addition, the standard errors of $b$ and $c$ were calculated, and the probability that these differed significantly from zero was determined by Student's ' $t$ ' test. Similar methods were used to investigate the relation between $R R$ interval and $\Delta \mathrm{P}$ and $\mathrm{PC}$ pressure.

All calculations were performed with an Olivetti 'Programma ror'.

TABLE 3 Relation between $R R^{\prime}$ and end-diastolic gradient across the prosthesis $\Delta(P)$ in Cases $\mathrm{I}-3$

\begin{tabular}{llllll}
\hline $\begin{array}{l}\text { Case } \\
\text { No. }\end{array}$ & State & $\begin{array}{l}\text { Slope } \\
(b)\end{array}$ & $\begin{array}{l}\text { Intercept } \\
(a) \\
(m m H g)\end{array}$ & $r$ & $P$ \\
\hline I & Rest & -0.066 & 85.5 & -0.83 & $<0.001$ \\
& Exercise & -0.081 & 86.3 & -0.70 & $<0.001$ \\
2 & Rest & -0.024 & 75.1 & -0.84 & $<0.001$ \\
& Exercise & -0.038 & 78.2 & -0.79 & $<0.001$ \\
3 & Rest & -0.043 & 83.6 & -0.87 & $<0.001$ \\
& Exercise & -0.035 & 76.8 & -0.58 & $<0.01$ \\
\hline
\end{tabular}

$\Delta \mathbf{P}=\mathbf{b} \times \mathbf{R} \mathbf{R}^{\prime}+\mathbf{a}$. 


\section{Results}

Ball travel time This was measured at rest and on exercise in 3 patients for 30 consecutive beats, and was in the range ro-60 msec. There was close correlation with QAI interval (Table 2), the slope and intercept of the regression lines being similar at rest and on exercise in the same patient.

End-diastolic gradient There was a highly significant negative correlation between $\mathbf{R} \mathbf{R}$ interval $\left(\mathbf{R} \mathbf{R}^{\prime}\right)$ and the immediately succeeding end-diastolic gradient across the prosthesis (Table 3). Multiple regression analysis showed no significant relation between $R^{\prime \prime}$ and end-diastolic gradient in any of the 3 cases.

Wedge pressure There was no significant relation between $R R^{\prime}$ or $R R^{\prime \prime}$ and end-diastolic wedge pressure either at rest or on exercise in any of the 3 cases (coefficient of multiple regression $0.26-0.32$ ).

QAr interval In all 19 patients there was highly significant correlation between QAI interval and one or both preceding $R R$ intervals. The results of multiple regression analysis are shown in Table 4. Correlation with the immediately preceding $R R$ interval $\left(R R^{\prime}\right)$ was always negative and highly significant, whereas that with $R^{\prime \prime}$ was present in only 14 out of the 19 patients, and, when significant, was always positive. These results are shown graphically for Case 15. In Fig. I, negative correlation between $R^{\prime}$ and $Q A I$ is shown, while when a population of beats is chosen such that $R R^{\prime}$ is within relatively narrow limits (in this case, I00 msec) then positive correlation with $\mathrm{RR}^{\prime \prime}$ is shown (Fig. 2).

In predicting QAI from the regression equations, its relative dependence on values of $\mathbf{R R}^{\prime}$ and $\mathbf{R} \mathbf{R}^{\prime \prime}$ is indicated by the magnitude of the constants $b$ and $c$ (Table 4). Though there was wide scatter in the values of these constants over the group as a whole in any individual case their magnitude was similar, though their sign was opposite.

\section{Discussion}

Measurement of the ball travel time, the time interval taken by the ball of a Starr-Edwards prosthesis in the aortic position to move from the base to the apex of the cage at the onset of left ventricular ejection, has previously been shown to be a sensitive index of the contractile state of the left ventricle (Gibson et al., 1970). Its determination requires the simultaneous recording of a phonocardio- gram and a central aortic pressure pulse which somewhat reduces the applicability of the method. However, close correlation has previously been shown, and is confirmed in the present study, between ball travel time, and QAI interval, the period between the onset of ventricular activation, and the opening sound of the prosthesis. QAI can be deter-

TABLE 4 Relation between $R R$ interval and $Q A I$ interval

\begin{tabular}{|c|c|c|c|c|c|c|c|}
\hline \multirow{3}{*}{$\begin{array}{l}\text { Case } \\
\text { No. }\end{array}$} & \multirow[t]{3}{*}{$r$} & \multirow{3}{*}{$\begin{array}{l}\text { Intercept } \\
(a) \\
(m s e c)\end{array}$} & \multicolumn{4}{|c|}{ Coefficients } & \multirow{3}{*}{$\begin{array}{l}\text { Standard } \\
\text { error of } \\
\text { estimate } \\
\text { (msec) }\end{array}$} \\
\hline & & & \multicolumn{2}{|c|}{$b\left(R R^{\prime \prime}\right)$} & \multicolumn{2}{|l|}{$c\left(R R^{\prime}\right)$} & \\
\hline & & & & $P$ & & $P$ & \\
\hline I & 0.94 & $8 I \cdot 5$ & 0.082 & $<0.001$ & -0.080 & $<0.001$ & 6.5 \\
\hline 2 & 0.94 & $67 \cdot 6$ & 0.051 & $<0.01$ & -0.11 & $<0.001$ & $8 \cdot 5$ \\
\hline 3 & 0.83 & 160.6 & 0.022 & Not significant & -0.067 & $<0.01$ & $6 \cdot I$ \\
\hline 4 & 0.90 & $99 \cdot I$ & 0.024 & $<0.01$ & -0.068 & $<0.001$ & $3 \cdot 6$ \\
\hline 5 & 0.95 & $83 \cdot 1$ & 0.060 & $<0.001$ & -0.097 & $<0.001$ & $3 \cdot 5$ \\
\hline 6 & 0.76 & $75 \cdot 3$ & 0.030 & $<0.01$ & -0.024 & $<0.01$ & $4 \cdot 6$ \\
\hline 7 & 0.82 & 89.9 & 0.005 & Not significant & -0.044 & $<0.01$ & $3 \cdot 8$ \\
\hline 8 & 0.95 & $144^{\circ} 0$ & 0.120 & $<0.001$ & -0.130 & $<0.001$ & I.5 \\
\hline 9 & $0: 73$ & $139^{\circ} 0$ & 0.076 & $<0.01$ & -0.074 & $<0.01$ & 15.3 \\
\hline Io & 0.87 & 150.3 & o.oro & Not significant & $-0.04 I$ & $<0.01$ & $9 \cdot 0$ \\
\hline II & 0.85 & $181 \cdot 9$ & 0.170 & $<0.01$ & -0.22 & $<0.001$ & 3.5 \\
\hline 12 & 0.88 & $122 \cdot 2$ & 0.015 & $<0.001$ & -0.016 & $<0.001$ & $5 \cdot 2$ \\
\hline I3 & 0.91 & $180 \cdot 7$ & 0.050 & Not significant & -0.173 & $<0.001$ & $I \cdot 7$ \\
\hline 14 & 0.96 & $94 \cdot 3$ & 0.127 & $<0.05$ & -0.139 & $<0.001$ & $I \cdot 2$ \\
\hline I5 & 0.91 & 143.0 & 0.170 & $<0.01$ & -0.180 & $<0.01$ & II $\cdot \mathbf{I}$ \\
\hline I6 & 0.78 & 158.0 & 0.038 & $<0.05$ & -0.054 & $<0.01$ & $12 \cdot 6$ \\
\hline 17 & 0.85 & $136 \cdot 2$ & 0.026 & $<0.05$ & -0.060 & $<0.001$ & $8 \cdot 5$ \\
\hline 18 & 0.88 & 123.9 & 0.027 & $<0.01$ & -0.040 & $<0.01$ & $3 \cdot 4$ \\
\hline 19 & 0.83 & $88 \cdot 4$ & 0.024 & Not significant & -0.052 & $<0.01$ & $7 \cdot 4$ \\
\hline
\end{tabular}

$\mathrm{QAI}=\mathrm{a}+\mathrm{bRR} \mathbf{R}^{\prime \prime}=\mathrm{cRR}$.

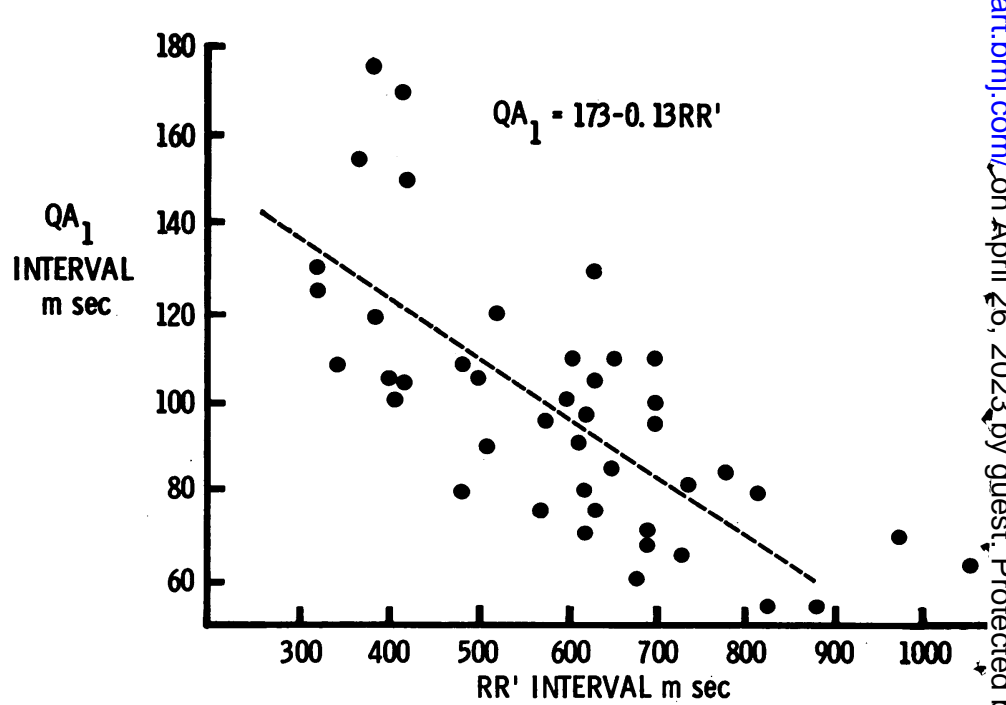

FIG. I Relation between $R R^{\prime}$ and $Q A I$

interval in Case 15. The regression line has

been derived from the multiple regression

equation in Table 4 by substitution of the mean

$R R$ interval (600 msec) for $R R^{\prime \prime}$. 
mined from simultaneous phonocardiogram and electrocardiogram and was used throughout the present study. As with ball travel time, a reduction in QAI interval implies an increase in the initial acceleration of the ball of the prosthesis, due to an increased force acting on it.

In intact man, variation in the interval between beats might affect the initial phase of left ventricular ejection in at least three ways. Prolongation of diastole might be associated with increased ventricular filling, while causing a reduction in aortic diastolic pressure, and therefore in the end-diastolic pressure gradient across the prosthesis. In addition, the interval between beats has a direct effect on the contractile state of the left ventricle (Bowditch, 1872). Though beat-to-beat changes in stroke volume have been documented in atrial fibrillation (Greenfield et al., I968), it has previously been shown that QAI interval is little affected by changes in left ventricular filling. This was confirmed in the present study by the lack of correlation between enddiastolic wedge pressure and QAI interval in three patients without significant mitral valve disease. It is likely, therefore, that the observed changes in QAI interval were due to beat-to-beat variation in the end-diastolic pressure gradient across the prosthesis, or to changes in the contractile state of the left ventricle directly related to pulse interval.

The end-diastolic pressure gradient across the prosthesis represents a force exerted over the area of the aortic orifice opposing that generated by the left ventricle. An increase in this gradient would therefore reduce the initial acceleration of the ball, the initial force generated by the ventricle remaining un- altered, and, if sufficiently large, might prevent the valve opening altogether. Thus, using

1 the present method, changes in the force generated by the left ventricle can only be

a substantiated when alterations in the enddiastolic pressure gradient have been eliminated as a cause of variation of QAI.

In all three patients there was highly significant negative correlation between $R R$ interval

- and the succeeding end-diastolic gradient across the prosthesis, both at rest and during $\rightarrow$ exercise. This was due to reduction in aortic diastolic pressure, since there was no relation between the RR interval and end-diastolic pulmonary wedge pressure. The longer the duration of diastole, the less was the force opposing that generated by the left ventricle, and it is therefore possible that the negative correlation between QAI interval and RR' $^{\prime}$ present in all 19 cases was, at least, partially due to this, though a direct effect of $R^{\prime}$ on

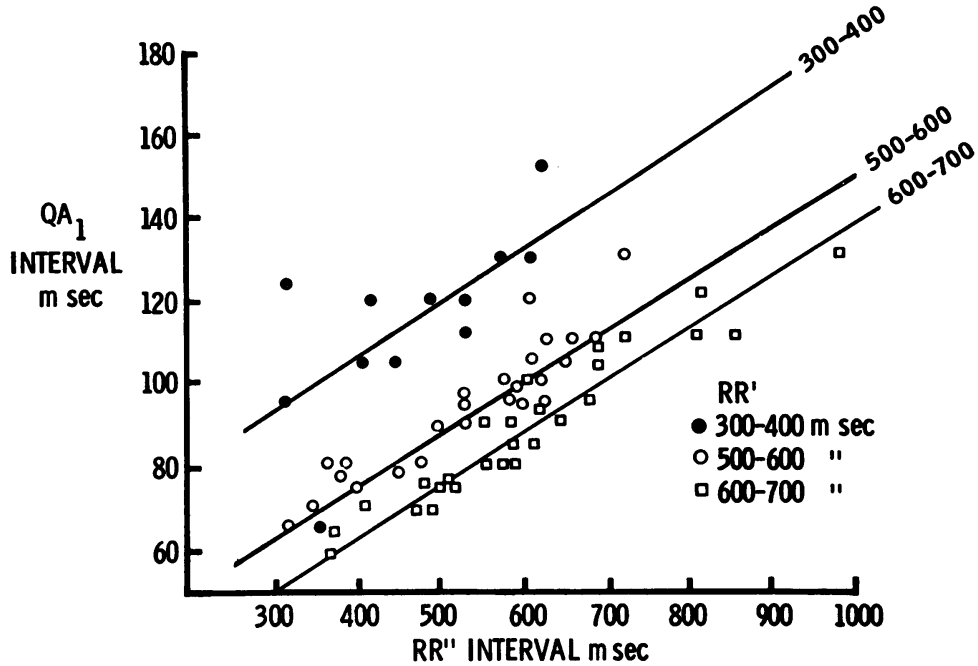

FIG. 2 Relation between $R R^{\prime \prime}$ and $Q A I$ interval in the same case as Fig. I for 3 groups of beats, for which $R R^{\prime}$ is 300-400 $\mathrm{msec}$, 500-600 $\mathrm{msec}$, and 600-700 $\mathrm{msec}$, respectively.

Correlation between $R^{\prime \prime}$ and $Q A I$ is positive, though at any given value of $R R^{\prime \prime}$, the longer $R R^{\prime}$ the shorter the $Q A I$ interval. The regression lines have been derived from the multiple regression equation in Table 4 by substitution of the mean $R R$ interval in each group for $R R^{\prime}$.

left ventricular contractile state has not been excluded.

In addition to the negative correlation between pulse interval and the succeeding QAI interval, there was positive correlation between pulse interval and QAr two beats later in 14 out of 19 patients, indicating that in intact man the characteristics of the initial phase of left ventricular ejection are determined by two, opposing, time-dependent processes. This second, positive correlation was not due to alterations in ventricular filling or to changes in the end-diastolic gradient across the prosthesis, and therefore it seems likely that the interval between beats had a direct effect on the contractile state of the left ventricle two beats later, causing a change in the initial force that it developed.

The dependence of the contractile state of the isolated heart on two opposing timedependent processes was first recognized by Woodworth (1902) who described 'the stimulating effect of a rapid succession of contractions and the recuperative effect of a long pause'. These effects have been studied in considerable detail by Koch-Weser and 
Blinks (1963) who have analysed them in terms of differences in the rates of decay of the positive and negative inotropic effects of activation. More recently, Meijler et al. (1968) have studied the effects of stimulation of the isolated heart at intervals derived from tape recordings of the electrocardiogram of patients with atrial fibrillation, and shown that beatto-beat variation in the contractile state occurred. They found strong positive correlation with the interval immediately preceding, while lesser, negative correlation existed for the previous second to tenth intervals. These results resemble the present ones, though we have been unable to dissociate the effects of $\mathbf{R R}^{\prime}$ on aortic impedance from a possible effect on left ventricular contractile state.

In 5 patients (Cases 3, 7, 10, 13, and 19) it was not possible to show significant correlation between RR $^{\prime \prime}$ and QAI interval. These patients all had clinical and radiological evidence of left ventricular failure with cardiac enlargement and pulmonary vascular congestion. This raises the possibility that in these patients the force generated by the left ventricle was at a maximum and that no further increase could occur as a result of variation in RR interval. This conclusion must remain tentative in view of the small number of patients in whom it was observed.

If the variation in QAI interval described by the regression equations derived in the present study were directly due to the interval between beats, then these relations should apply to circumstances other than atrial fibrillation. The coefficients describing the dependence of QAI on $R R^{\prime \prime}$ and $R R^{\prime}$ ( $b$ and c) were approximately equal in magnitude and opposite in sign. It follows, therefore, that when the heart rhythm is regular, i.e. when $\mathbf{R R}^{\prime}$ is equal to $\mathbf{R R}^{\prime \prime}$, $\mathbf{Q A I}$ should be almost independent of rate. This was seen in patients in sinus rhythm in whom heart rate was increased by atropine administration or ventricular pacing (Gibson et al., 1970). For a single premature beat with normal ventricular activation, $R^{\prime}$ is less than $\mathbf{R R}^{\prime \prime}$ and therefore the beat itself might be expected to be weaker than control, while for the post-ectopic beat $\mathbf{R R}^{\prime \prime}$ is short, and $R \mathbf{R}^{\prime}$ often longer than the sinus rate so that QAI should be shorter than control indicating increased force of ventricular contraction.

In addition, certain clinical features of atrial fibrillation follow from the regression equations. 'Missed beats' are those in which the force of left ventricular contraction is insufficient to open the aortic valve, and in them the QAI interval may be regarded as being very long. It follows that they might be expected to occur when $R R^{\prime \prime}$ is long and $R R^{\prime}$ short, and so are a function of irregularity of the rhythm rather than of a rapid rate. When the reverse conditions occur, i.e. $\mathbf{R R}^{\prime \prime}$ is short and $R^{\prime}$ long, $Q A I$ is very short, implying an inappropriately powerful left ventricular contraction. Since the contractile state of the left ventricle is an important determinant of myocardial oxygen consumption (Graham et al., 1968), such inappropriate increases in contractility reduce the external efficiency of the heart. In addition, continual changes in aortic impedance might impair left ventricular performance even in the absence of changes in contractile state. Wilcken et al. (1964) have shown that under conditions of constant aortic impedance, the left ventricle operates at maximal external work and power, and that these are reduced by a sudden change in aortic pressure. Reduction in the performance of the left ventricle might therefore occur in atrial fibrillation by mechanisms that are unrelated to the loss of atrial contraction, but which are due to irregularity of the $R R$ interval.

We are grateful to Janet Woods and Mr. G. Castle for skilled technical assistance, and to the consultants at the National Heart Hospital for permission to study their patients.

\section{References}

Bowditch, H. P. (1872). Úber die Eigenthümlichkeiten der Reizbarkeit, welche die Muskelfasern des Herzens zeigen. Berichte über die Verhandlungen der königlich sächsischen Gesellschaft der Wissenschaften zu Leipzig. Mathematisch-physische Classe, $I 87 I, 23$, p. 652.

Einthoven, W., and Korteweg, A. J. (I915). On the variability of the size of the pulse in cases of auricular fibrillation. Heart, 6, 107.

Gibson, D. G., Broder, G., and Sowton, E. (1970). Phonocardiographic method of assessing changes in left ventricular function after Starr-Edwards replacement of aortic valve. British Heart fournal, 32, 142.

Graham, T. P., Jr., Covell, J. W., Sonnenblick, E. H., Ross, J., Jr., and Braunwald, E. (1968). Control of myocardial oxygen consumption: relative influence of contractile state and tension development. fournal of Clinical Investigation, 47, 375.

Greenfield, J. C., Harley, A., Thompson, H. K., and Wallace, A. G. (1968). Pressure-flow studies in man during atrial fibrillation. Fournal of Clinical Investigation, 47, $241 \mathrm{I}$.

Koch-Weser, J., and Blinks, J. R. (1963). The influence of the interval between beats on myocardial contractility. Pharmacological Reviews, 15, 601.

Meijler, F. L., Strackee, J., van Capelle, F. J. L., and du Perron, J. C. (1968). Computer analysis of the $R R$ interval-contractility relationship durlng random stimulation of the isolated heart. Circulation Research, 22, 695. 
Wiggers, C. J. (I915). Studies on the pathological physiology of the heart. I. The intra-auricular, intraventricular and aortic pressure curves in auricular fibrillations. Archives of Internal Medicine, $15,77$.

Wilcken, D. E. L., Charlier, A. A., Hoffman, J. I. E., and Guz, A. (1964). Effects of alterations in aortic impedance on the performance of the ventricles. Circulation Research, 14, 283.

Woodworth, R. S. (1902). Maximal contraction, 'staircase' contraction, refractory period, and compensatory pause, of the heart. American fournal of Physiology, 8, 213. 